\title{
The cycles of impermanent alterity in Nazaré
}

\author{
Cidália Ferreira Silva \\ Lab2PT/EAUM \\ cidalia@arquitectura.uminho.pt \\ Marisa Carvalho Fernandes \\ EAUM \\ marisacarvalhofernandes@gmail.com
}

What happens when a small city expands from 15000 to 100000 inhabitants in the summer time?

Because of its extensive beach and remarkable waves Nazaré has been a vacation destination since the 50s.

Tourists from all over the world come here between July and September to enjoy this landscape. Who and

how many come here? How do these temporary inhabitants change the rhythms of Nazaré's everyday life?

How do year-round residents adapt to embrace so many 'others'? How do both interact and create

connections that last long after a once a-year visit, or repeating year after year to return to the same place and

to 'friends' they left? How does this massive tourism change the supporting life activities of Nazaré's

inhabitants becoming complementary to the fishing activity, or even replacing it? Is this seemingly rigid urban fabric elastic enough to expand and adapt to these exponential 'others'?

Impermanent alterity explains the relationship between land and water, between 'I' and the 'other' that comes here to step onto the warm sand during the summer days, making visible the cycles of summer-winter, by unfolding their network of lived time interconnections in simple things like the grey line organizing the sidewalk appropriation, a device that adapts matter to the cycles of change. Many others exist.

Time is the operator of this impermanent alterity. How do we make it visible? According to Corner, (1999) it is through mapping, a practice of creative representation that crosses fieldwork with interdisciplinary data. The results presented here are part of a larger research presented at EAUM.

short abstract

What happens when a small city expands from 15000 to 100000 inhabitants in the summer time?

Impermanent alterity explains the relationship between land and water, between 'I' and the 'other,' making visible the cycles of summer-winter, by unfolding their network of lived time interconnections. 